\title{
RESSIGNIFICAR A DOCÊNCIA: \\ PRÁTICAS NA FORMAÇÃO DE PROFESSORES A PARTIR DO PROGRAMA DE RESIDÊNCIA PEDAGÓGICA
}

Alcicley Mendes Cardoso ${ }^{1}$ Jadson dos Santos ${ }^{2}$

A experiência aqui registrada em fotografias trata-se das observações realizadas nas aulas de Educação Física (EF) de uma turma do $6^{\circ}$ ano do Ensino Fundamental na Escola Maestro João Leite na Cidade de Tucuruí no Estado do Pará. O registro centraliza-se na experiência de um acadêmico do Curso de EF e um professor graduado atuante na rede educacional deste município, ambos participantes do programa Residência Pedagógica da Universidade do Estado do Pará, que tematiza as "Práticas Pedagógicas da Educação Física: para além da pedagogia do toma bola" articulando a formação de professores e a realidade da escola pública.

O que aludimos sobre "pedagogia do toma bola", trata-se de atuações docentes que afastam-se de uma proposta pedagógica direcionada e intencional, onde a prática do professor fica restrita à organização do espaço e dos materiais didáticos/esportivos durantes as aulas de EF. Silva e Bracht (2012) também denominam este fenômeno como desinvestimento pedagógico, e em suas críticas apontam como possível causas deste fenômeno a desarticulação entre teoria e prática na formação de professores.

O Episódio aqui registrado apresenta uma sequência de eventos que visou aproximar a formação docente do acadêmico em questão com a realidade do campo de atuação da EF escolar, acompanhado pelo professor regente da turma. Percebemos na ocasião que o conteúdo tematizado (esporte voleibol) desperta a atenção dos alunos, Silva (2013) aponta como possível causa deste destaque dos esportes nas aulas de EF, o fato de ser este conteúdo um dos maiores fenômenos da atualidade, uma linguagem que por meio das suas regras, ritos, competições internacionais e o comércio de marcas esportivas, ecoa pelo mundo todo despertando alegrias, sonhos e ilusões. Esta hiper valorização deste fenômeno carrega consigo

\footnotetext{
${ }^{1}$ Mestre em Educação pela Universidade do Estado do Pará. Especialista em Ensino de Educação Física Escolar pela Faculdade Venda Nova do Imigrante. Preceptor no Programa de Residência Pedagógica - UEPA/CAPES. Professor da Educação Básica nos Anos Finais. Email: kleyuepa@gmail.com.

${ }^{2}$ Graduando no curso de Licenciatura em Educação Física no $8^{\circ}$ semestre do curso. Universidade do Estado do Pará, Campus XIII Tucuruí. Residente do Programa de Residência Pedagógica - UEPA/CAPES. Email: jadsonsaneamento@msn.com.
} 
as contradições e valores da sociedade atual. Por este fato, os esportes devem ser tematizados na escola de forma crítica, dialógica e ressignificada, e não meramente praticado pelos alunos.

A composição deste ensaio consistiu no registro fotográfico realizada numa escola pública no dia 18 de outubro de 2019, que atende discentes de bairros periféricos da referida cidade. Centralizou-se em destacar a importância da qualificação da formação de professores de EF por meio da articulação entre teoria e prática, universidade e escola e pesquisa e ação.

\section{REFERÊNCIAS}

SILVA, Mauro Sérgio; BRACHT, Valter. Na pista de práticas e professores inovadores na educação física escolar. Periódicos: UFSM. 2012.

SILVA, J. V. P. da. Prática pedagógica em educação Física nos anos iniciais do Ensino Fundamental. Pensar a Prática, Goiânia, v. 16, n. 1, p. 1.319, jan./mar. 2013.

Recebido em: 18/12/2019

Aprovado em: 18/12/2019 

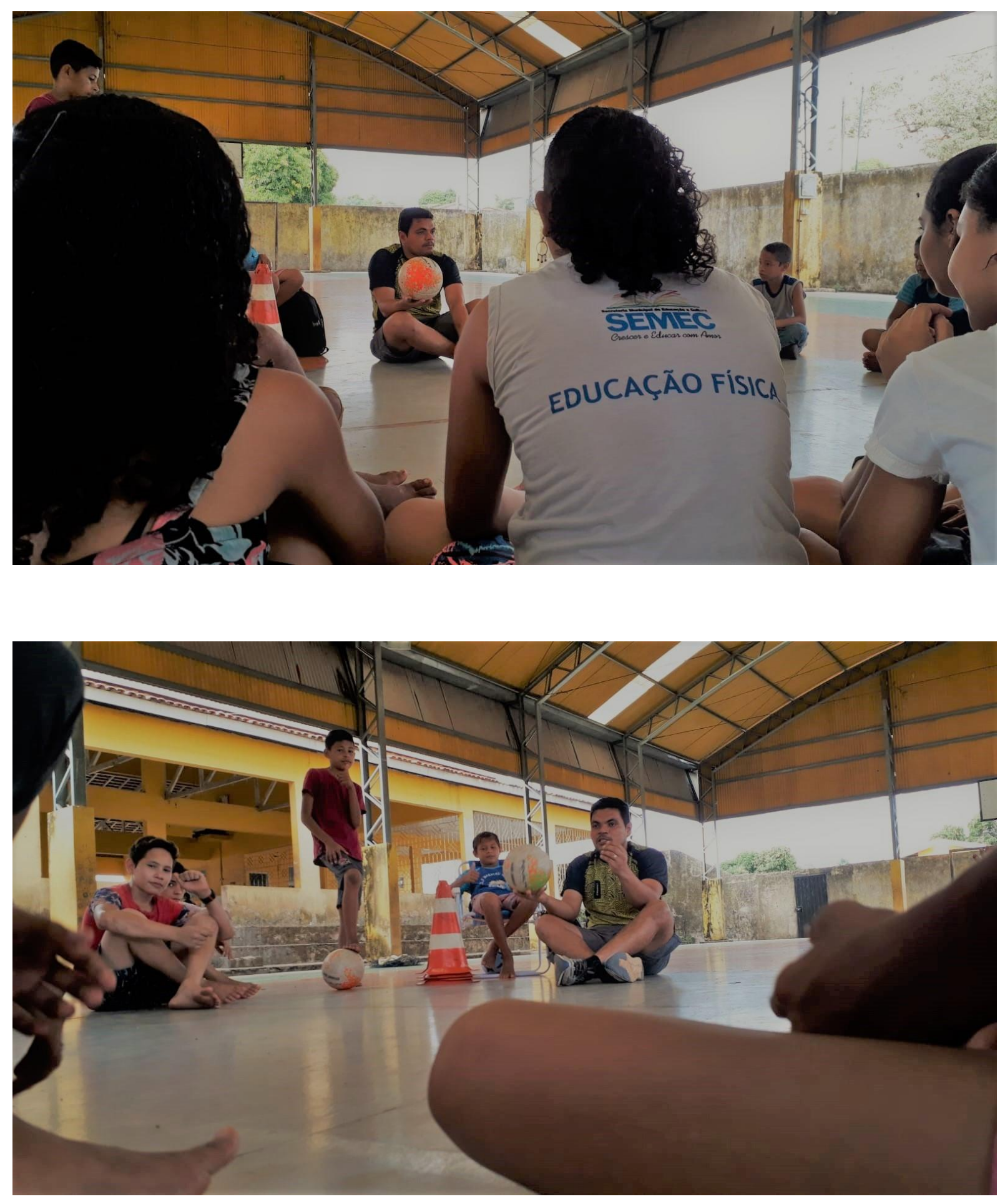

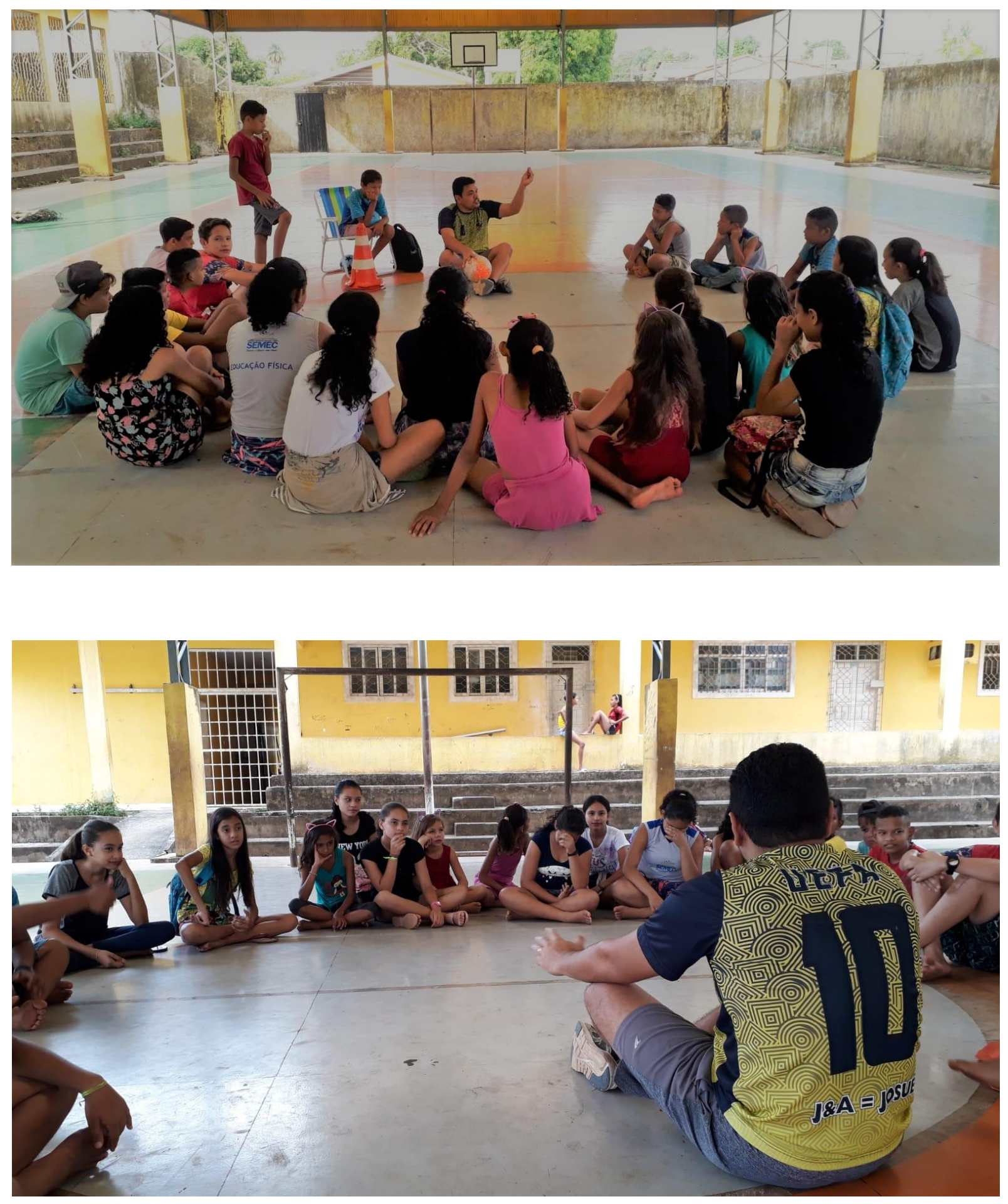

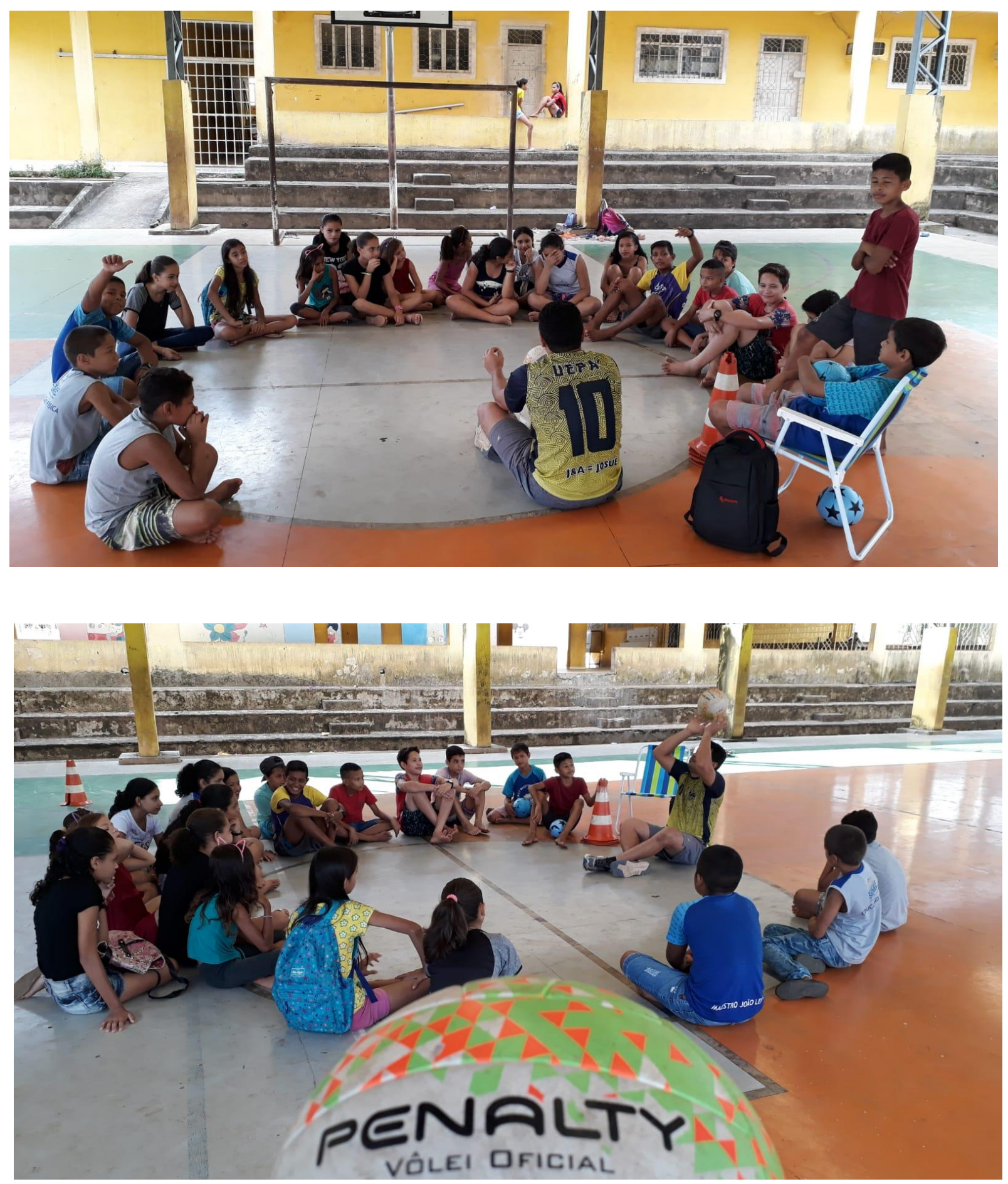

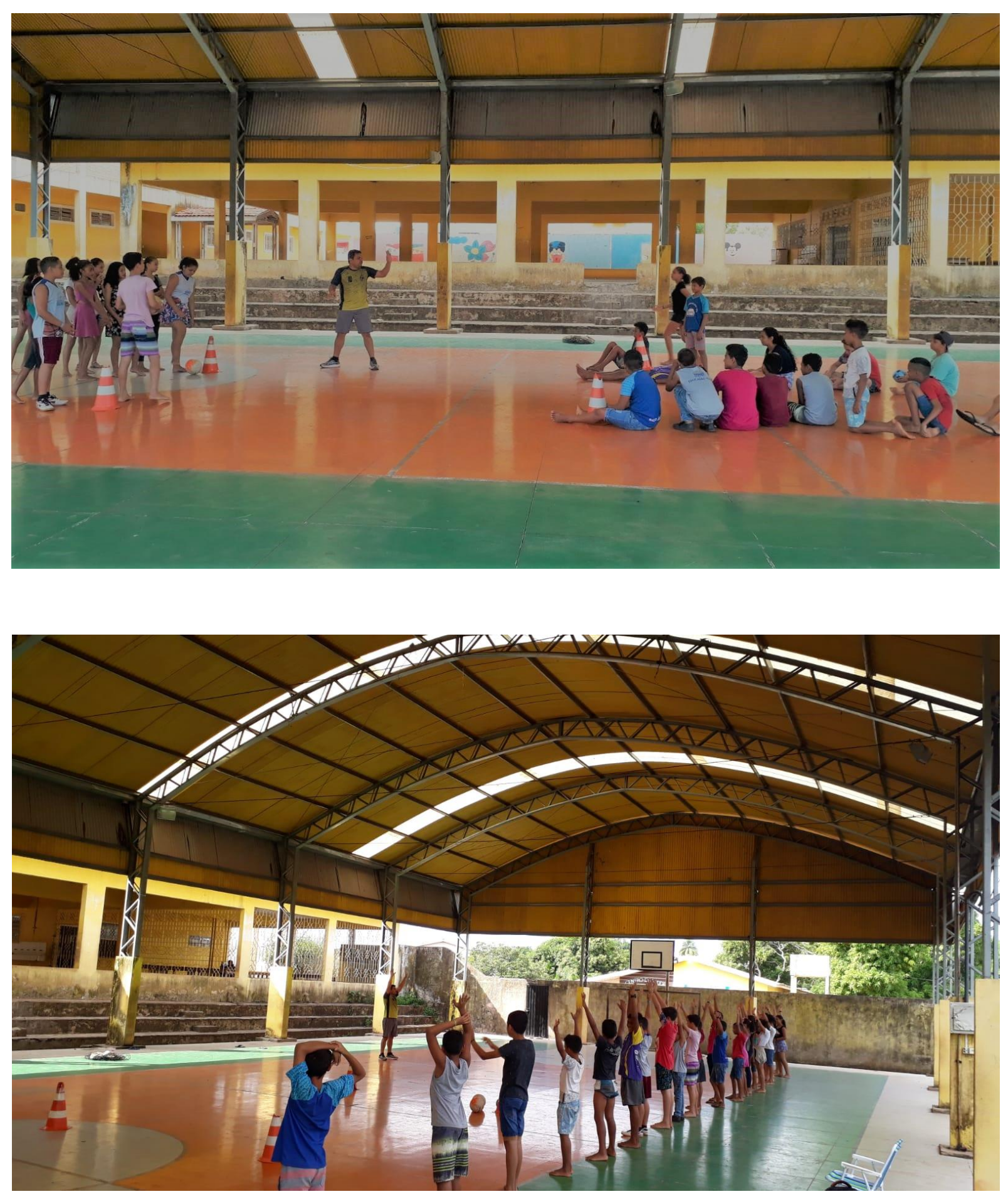

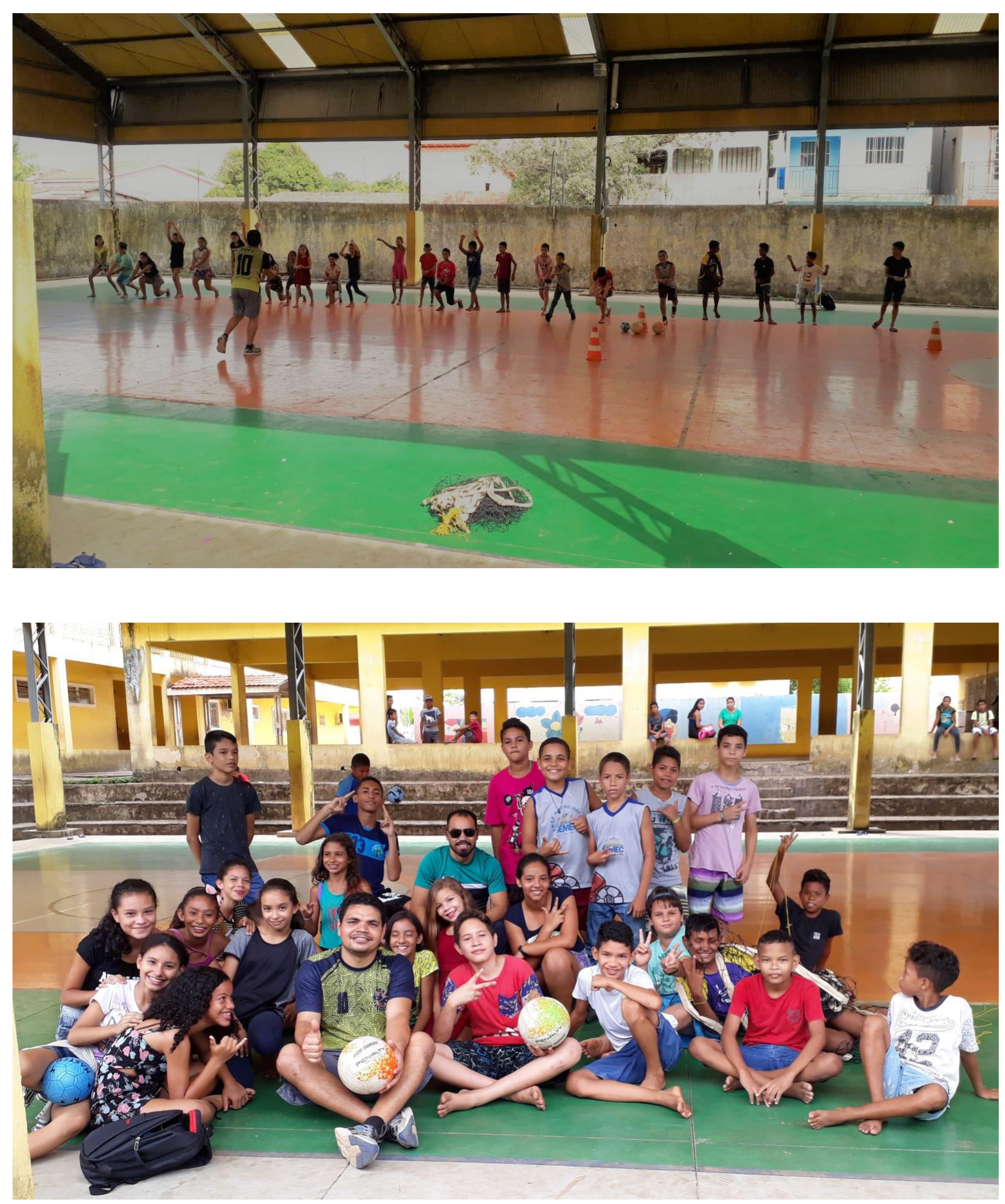